\title{
A new journal in the field of child neurology: Journal of Pediatric Neurology
}

\author{
Hüseyin Çaksen
}

Yüzüncü Yll University Faculty of Medicine, Department of Pediatric Neurology, Van, Turkey

\section{Dear Colleagues:}

I take pride, with this maiden issue to introduce you to our new journal, the Journal of Pediatric Neurology. This journal is a peer-reviewed medical journal that publishes articles in the field of child neurology, pediatric neurosurgery, pediatric neuroradiology, child psychiatry and pediatric neurosciences. Each issue would present to the readers, the current developments in a broad spectrum of child neurology. I believe that this journal, the Journal of Pediatric Neurology would participate in the research and development of child neurology over the coming years, by publishing informative and innovative articles from all disciplines.

In recent times with the advancements in diagnostic aids, more and more new disorders and syndromes are being described, an insight to their pathophysiological mechanisms are being understood. Knowledge of these disorders in pediatric neurology would help researchers to formulate management protocols by which child health would improve as a whole. With this primary aim, I introduce to the world of medical researchers this new journal, the Journal of Pediatric Neurology.

The Journal of Pediatric Neurology would be a valuable addition and contribution in the field of pediatric neurosciences for the overall neurological management of a child both among developed and developing nations. Our editorial and advisory board includes some of the most enthusiastic, diligent and productive specialists working in the field of pediatric neurology.

Comprised of members from developed and developing countries it enables us to broaden the range of research and ensure a wide spread distribution of the Journal of Pediatric Neurology. I extend my sincere gratitude and thanks to all the members of the journal's editorial and advisory board.

To conclude, I would like to especially thank my wife for her constant support and valued assistance during the hard work and effort put in, in the preparation of this journal. I also take the opportunity to thank Prof. Gülhis Deda, who embedded in me the knowledge of Pediatric Neurology with her vast experience. Finally, I thank Prof. Dursun Odabaş, the founder and Head of Department of Pediatrics, Yüzüncü Yıl University for his constant encouragement and unending support till the final launch of the journal.

Looking forward to years to quality issues.

With best wishes from Turkey.

Correspondence: Hüseyin Çaksen, M.D.,

Editor-in-Chief,

Journal of Pediatric Neurology,

Yüzüncü Y1l University Faculty of Medicine,

Department of Pediatric Neurology,

PO Box 2,

65100 Van, Turkey.

Tel: 0904322159164.

Fax: 0904322150479 .

E mail: huseyincaksen@hotmail.com 